\title{
Renal arteriovenous fistula after retrograde ureteroscopic lithotripsy for the lower ureteral stones: a rare case report
}

\author{
Wan-Zhang Liu, Ting Huang, Li Fang and Yue Cheng*
}

\begin{abstract}
Background: Renal arteriovenous fistula was rarely reported in retrograde endoscopic procedure. Up to now, there is still an absence of report on the formation of renal arteriovenous fistula after semi-rigid ureteroscopic lithotripsy for lower ureteral stones.

Case presentation: An 83-year-old man was admitted to our hospital complaining about intermittent left flank pain that had persisted for 1 week. He suffered medium hypertension and nephrolithiasis treated with left open ureterolithotomy and two ureteroscopic lithotripsies. Non-contrast abdominal CT scan revealed two left lower ureteral stones diametered $8 \mathrm{~mm}$ and $7 \mathrm{~mm}$ respectively with mild hydronephrosis. A retrograde semi-rigid ureteroscopic lithotripsy was performed to remove the stones, after which two Double-J stents were placed for the ureteral stricture. Due to the continuous gross hematuria and hemoglobin droppings 2 days after operation, a variety of conservative therapies, including blood transfusion and bed rest, were adopted. Then, the patient was discharged with a stable hemoglobin. However, he presented himself to our emergency department with aggravating left flank pain and severe gross hematuria as little as 2 days later. Emergent digital subtraction angiography was conducted to reveal an arteriovenous fistula in the left kidney, which was embolized with two platinum coils to stop the bleeding. His hematuria was resolved in 3 days, and two Double-J stents were removed in 4 weeks. The patient was followed up for 1 year, during which no hematuria or flank pain recurred.

Conclusion: This is the first case report on the formation of renal arteriovenous fistula after semi-rigid ureteroscopic lithotripsy. In this case, elevated intrapelvic pressure, historical surgery and hydronephrosis might be associated with the primary risk of the complication.
\end{abstract}

Keywords: Renal arteriovenous fistula, Severe bleeding, Computed tomography angiography, Digital subtraction angiography, Case report

\section{Background}

At present, retrograde semi-rigid URSL has been commonly applied in the observation and treatment of ureteral diseases. It is widely known that, the incidence of postoperative complications is low, mostly manifested as Grade I and II, for example, renal colic, infection,

\footnotetext{
* Correspondence: chengyueur@qq.com

Department of Urology, NingBo First Hospital, NingBo Hospital of ZheJiang University, \#59 Liuting Street, NingBo City 315000, Zhejiang Province, China
}

ureteral injury and hematuria [1]. The formation of AVF after retrograde procedure was rarely seen, as a result of which there have been few reports on the retrograde intrarenal lithotripsy for renal stones over the past two decades [2]. Therefore, a patient exhibiting an AVF after semi-rigid URSL in the treatment of the lower ureteral stones is reported in this study, and the relevant literature is reviewed.

(c) The Author(s). 2020 Open Access This article is licensed under a Creative Commons Attribution 4.0 International License, which permits use, sharing, adaptation, distribution and reproduction in any medium or format, as long as you give appropriate credit to the original author(s) and the source, provide a link to the Creative Commons licence, and indicate if changes were made. The images or other third party material in this article are included in the article's Creative Commons licence, unless indicated otherwise in a credit line to the material. If material is not included in the article's Creative Commons licence and your intended use is not permitted by statutory regulation or exceeds the permitted use, you will need to obtain permission directly from the copyright holder. To view a copy of this licence, visit http://creativecommons.org/licenses/by/4.0/. The Creative Commons Public Domain Dedication waiver (http://creativecommons.org/publicdomain/zero/1.0/) applies to the data made available in this article, unless otherwise stated in a credit line to the data. 


\section{Case presentation}

An 83-year-old man was referred to our clinic in May 2019 for the complaint about intermittent left flank pain that had persisted for 1 week. Despite the denial of fevers, dysuria, hematuria, frequency or urgency, he admitted to visiting local clinics and receiving medical therapies. Besides, this patient had medium hypertension and nephrolithiasis treated with left open ureterolithotomy and two URSLs.

Though routine urinalysis revealed $40 \mathrm{WBC} / \mathrm{ul}$ and 48 $\mathrm{RBC} / \mathrm{ul}$, the result of urine culture was negative. As revealed by non-contrast abdominal CT scan, there were two left lower ureteral stones diametered $8 \mathrm{~mm}$ and 7 $\mathrm{mm}$ respectively with mild hydronephrosis, as shown in Fig. 1a. In addition, kidney, ureter, bladder (KUB) plain film indicated two lower ureteral stones, as show in Fig. $1 b$. In spite of this, both preoperative physical examination and laboratory study revealed no abnormality. After the identification of left ureteral stones, semi-rigid URSL with holmium laser was adopted. The surgery was performed by a surgeon with more than 5 years of specialist experience.

As preparation for the operation, the general anesthesia was conducted for $47 \mathrm{~min}$. With the patient was left in the lithotomy position, a 6/7.5-Fr semi-rigid ureteroscope (Storz, Germany) with $220 \mu \mathrm{m}$ holmium laser was applied to smash the stones. Upon close examination, an ureteral stricture was found beneath the stones, and the semi-rigid ureteroscope passed it carefully with the guidance of a guide wire. For improved visibility, a hand-pump irrigation was carried out by an assistant. The process of smashing stone continued until the visible fragments were $\leq 3 \mathrm{~mm}$ in diameter, with most of them extracted into the bladder using a basket. Finally, two 5Fr Double-J stents were placed due to the ureteral stricture and an urethral catheter was indwelled.
The patient displayed slight left flank pain and continuous hematuria after the surgery, which was considered as a complication of Double-J stents. Normal blood tests indicated severe droppings of hemoglobin from $103 \mathrm{~g} / \mathrm{dL}$ to $61 \mathrm{~g} / \mathrm{dL} 2$ days after operation. Low dose abdominal CT-scan revealed mild left hydronephrosis with blood clots, while no remains of stones were observed in the ureter, as shown in Fig. 2a. KUB showed two ureteral stents in the left urinary tract, as shown in Fig. 2b. Due to the continuous gross hematuria and droppings of hemoglobin, various conservative therapies, including blood transfusion $(600 \mathrm{ml}$ of red blood cells in total), antibiotics (sulbenicillin) and bed rest, were carried out. After 10 days of observation in hospital, the patient was discharged with a slight hematuria and stable hemoglobin level $(84 \mathrm{~g} / \mathrm{dL})$. Over the course of observation, creatinine and other laboratory tests invariably showed compliance with the specified limits. Moreover, the patient was instructed to remove his two Double-J stents in 4 weeks.

Two days later, he presented himself to our emergency department with aggravating left flank pain and severe gross hematuria. Four thousand seven hundred eightythree $\mathrm{RBC} / \mathrm{ul}$ and $364 \mathrm{WBC} / \mathrm{ul}$ were detected through urinalysis. Blood test revealed low hemoglobin level at $54 \mathrm{~g} / \mathrm{dL}$. According to the multi-detector computed tomography angiography and three-dimensional construction of renal arteries, there was an AVF and contrast leakage into calices in the left kidney, as shown in Fig. 3a and Fig. 3b. Then, the findings were confirmed by emergent digital subtraction angiography, as shown in Fig. 4a. Additionally, the AVF was embolized with two platinum coils to stop bleeding, as shown in Fig. 4b. In the meantime, blood transfusion was conducted until the hemoglobin levels reached $70 \mathrm{~g} / \mathrm{dL}$. Hematuria was resolved in 3 days and two Double-J stents were removed

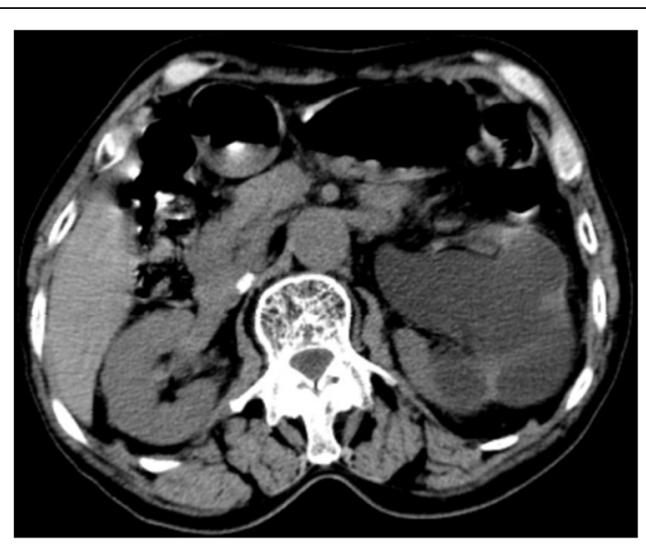

a

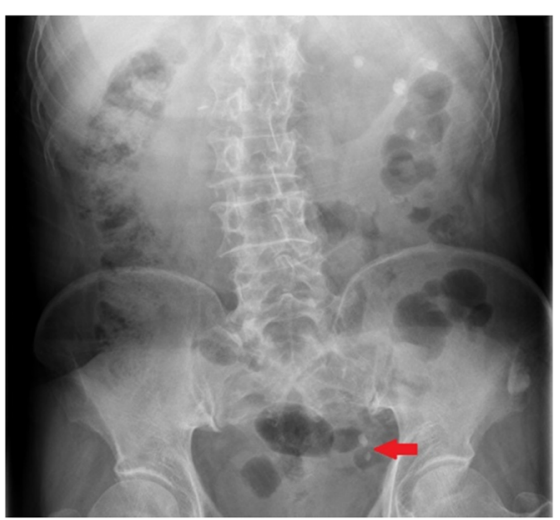

b

Fig. 1 a CT revealed mild hydronephrosis in the left kidney. b KUB exhibited two lower ureteral stones 


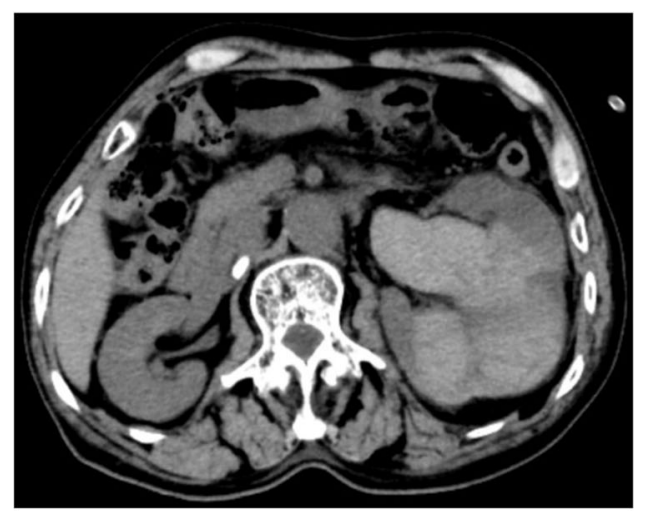

a

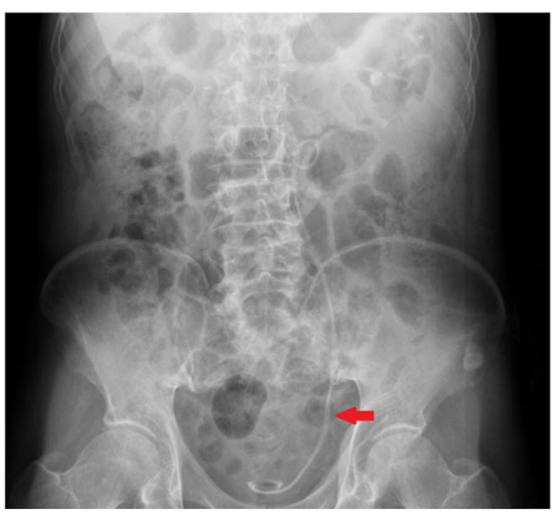

$\mathrm{b}$

Fig. 2 a CT revealed mild left hydronephrosis with blood clots. b KUB showed two ureteral stents in the left ureter

1 month later. During the 12-month follow-up, no hematuria or flank pain recurred.

\section{Discussion and conclusion}

Despite renal hemorrhage as a common complication caused by urological endoscopic procedure, it was mostly studied in percutaneous operations, such as PCNL. It might be manifested as pseudoaneurysm, AVF, bleeding spot and combined [3]. Since the kidney is classed as a vascular organ, bleeding might occur as a result of the damage caused to the renal substances, like the introduction of needle, dilatation of tract, fragmentation of stones and elevated intrarenal pressure. In spite of conservative therapies, further digital subtraction angiography and embolization are required to stop bleeding for those with continuous gross hematuria and a severe hemorrhage (hemoglobin dropping $>30 \mathrm{~g} / \mathrm{dL}$ ) [4].
Different from PCNL, retrograde ureteroscopic surgery is completely performed through the urinary tract, so as to avoid the potential substantial damage caused to the kidney. Thus, the incidence of renal hemorrhage following retrograde procedures was extremely low (0.15$0.4 \%$ ) [5-7], and it was mostly manifested as subcapsular and perinephric hematoma. It was believed that the damage caused to pelvicalyceal system by guide wire and the elevated intrarenal pressure leading to the rupture of renal parenchyma might be attributed to bleeding [7]. Kozminski [8] suggested that renal hematoma is associated with such factors as female gender, preoperative hypertension, preoperative ureteral stenting, intraoperative ureteral sheath use, and postoperative ureteral stenting. Tiplitsky [2] presented a case of intrarenal arteriovenous fistula after the flexible ureteroscopic extraction of stone with holmium laser lithotripsy, which led to the finding that the damage caused to interlobar

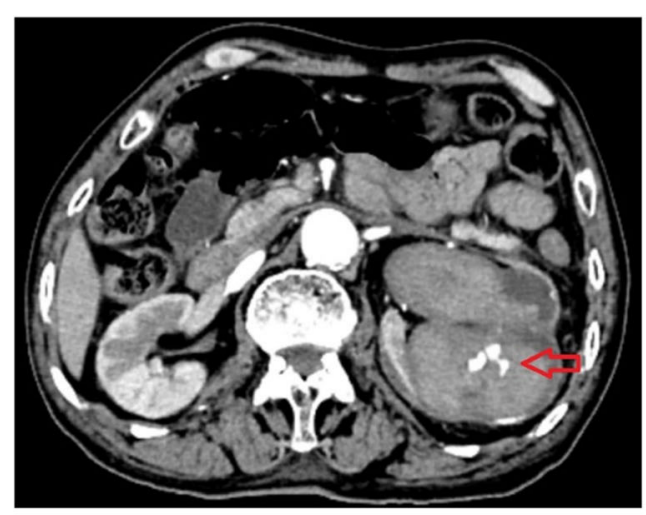

a

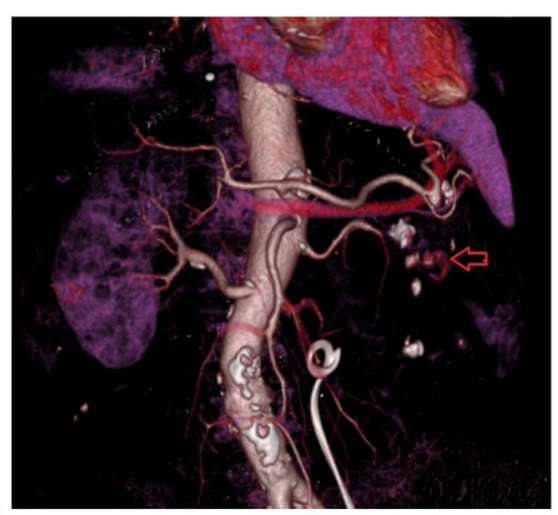

b

Fig. 3 a multi-detector computed tomography angiography showed mild hydronephrosis with blood clots and AVF in the left kidney. $\mathbf{b}$ threedimensional construction of renal arteries found an AVF 


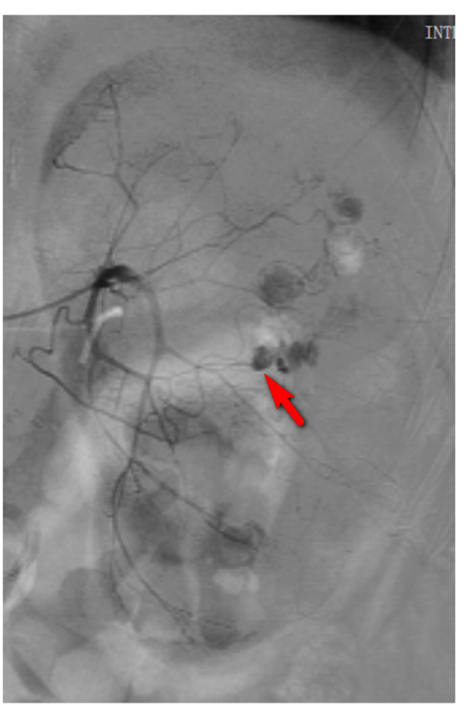

a

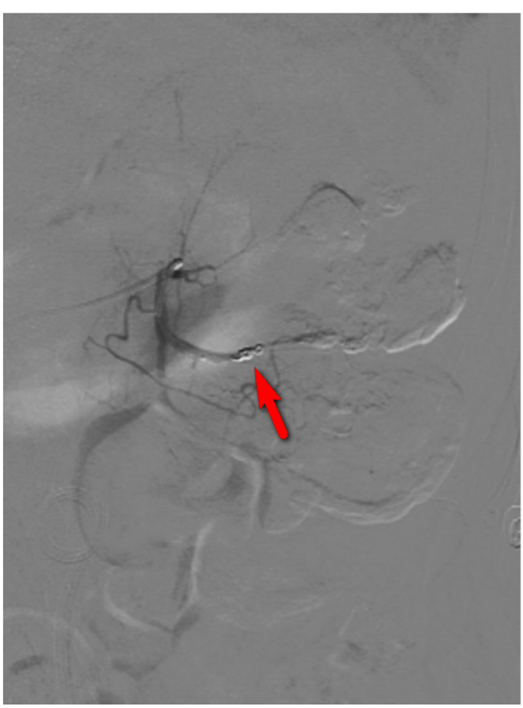

b

Fig. 4 a digital subtraction angiography revealed an AVF in the left kidney. $\mathbf{b}$ the AVF was embolized with two platinum coils

arteries by holmium laser was the most likely root cause. As we known, there is still no report on the formation of AVF following semi-rigid ureteroscopic lithotripsy for the lower ureteral stones.

In our case, the elevated intrapelvic pressure during the process of smashing stones is supposed to be the leading cause of AVF and bleeding. On the one hand, the ureteral stricture beneath the stones could reduce not only the gap between the ureteral wall and the ureteroscope, but also the outflow of irrigative fluid as a consequence. Secondly, a hand-pump irrigation, performed by an assistant, provided a high irrigative pressure to ensure the sufficient visibility. In the meantime, however, it caused the intrarenal pressure to increase. But we were not able to measure the exact pressure during the surgery. On the other hand, a long-term hydronephrosis and previous surgery histories could have a detrimental effect on the substantial of kidney, thus leading to the potential formation of AVF.

It marks the first case in relation to the formation of AVF after semi-rigid ureteroscopic procedure, but the exact physiopathology remains unclear. To our knowledge, the elevated intrapelvic pressure that might lead to the rupture of renal parenchyma was mainly responsible for the complication. For the patients with a ureteral stricture beneath the stones, the double-J stent should be placed 2-4 weeks in advance to facilitate the passage of endoscope and the outflow of irrigation while the smashing of stones proceeds. Although the usage of double ipsilateral ureteral stents achieved a higher success rate than single stent in the treatment ureteral strictures after an endoureterotomy [9], the efficiency of two stents placement without an endourological technique in this case is still lack of evidence. Finally, surgeons must be aware of the outflow of irrigative fluid, but not always a good visibility during the smashing of stones.

\section{Abbreviations \\ AVF: Arteriovenous fistula; URSL: Ureteroscopic lithotripsy; WBC: White blood cell; RBC: Red blood cell; CT: Computed tomography; PCNL: Percutaneous nephrolithotomy}

\section{Acknowledgments \\ None.}

\section{Authors' contributions}

WZL: Design and drafting of the article, and final approval of the version to be submitted. TH: Data acquisition, drafting of the article, and final approval of the version to be submitted. LF: Data acquisition, critical revision of the article, and final approval of the version to be submitted. YC: Critical revision of the article, and final approval of the version to be submitted.

Funding

No funding to declare for this article.

Availability of data and materials Not applicable.

Ethics approval and consent to participate

This case report was approved by the institutional ethical committee in our hospital, and written informed consent was obtained from the patient.

\section{Consent for publication}

Written informed consent was obtained from the patient for publication of this case report and any accompanying images. A copy of the written consent is available for review by the Editor of this journal.

Competing interests

The authors declare that they have no competing interests. 
Received: 30 May 2020 Accepted: 29 July 2020

Published online: 15 August 2020

\section{References}

1. Geavlete P, Georgescu D, NiTA G, et al. Complications of 2735 retrograde Semirigid Ureteroscopy procedures: a single-center experience. J Endourol. 2006;20(3):179-85.

2. Tiplitsky SI, Milhoua PM, Patel MB, et al. Case report: Intrarenal Arteriovenous fistula after Ureteroscopic stone extraction with holmium laser lithotripsy. J Endourol. 2007;21(5):530-2.

3. Ganpule AP, Shah DH, Ganpule SA, et al. Role of multi-detector computed tomography (MDCT) in management of post percutaneous nephrolithotomy (PCNL) bleeding. F1000 Res. 2013;2:253.

4. Choi MJ, Kim PH, Shin JH, et al. Angiographic management of percutaneous renal procedure-related bleeding: a single-center experience. Int J Urol. 2019;26(3):406-12.

5. Tao W, Cai CJ, Sun CY, et al. Subcapsular renal hematoma after ureteroscopy with holmium:yttrium-aluminum-garnet laser lithotripsy. Lasers Med Sci. 2015;30(5):1527-32.

6. Chiu KF, Chan CK, Ma WK, et al. Subcapsular hematoma after Ureteroscopy and laser lithotripsy. J Endourol. 2013;27(9):1115-9.

7. Bansal U, Sawant A, Dhabalia J. Subcapsular renal hematoma after ureterorenoscopy: an unknown complication of a known procedure. Urol Ann. 2010;2(3):119-21.

8. Kozminski MA, Kozminski DJ, Roberts WW, et al. Symptomatic subcapsular and Perinephric hematoma following Ureteroscopic lithotripsy for renal calculi. J Endourol. 2015;29(3):277-82.

9. Ibrahim HM, Mohyelden K, Abdel-Bary A, et al. Single versus double ureteral stent placement after laser Endoureterotomy for the Management of Benign Ureteral Strictures: a randomized clinical trial. J Endourol. 2015; 29(10):1204-9.

\section{Publisher's Note}

Springer Nature remains neutral with regard to jurisdictional claims in published maps and institutional affiliations.

Ready to submit your research? Choose BMC and benefit from:

- fast, convenient online submission

- thorough peer review by experienced researchers in your field

- rapid publication on acceptance

- support for research data, including large and complex data types

- gold Open Access which fosters wider collaboration and increased citations

- maximum visibility for your research: over $100 \mathrm{M}$ website views per year

At $\mathrm{BMC}$, research is always in progress.

Learn more biomedcentral.com/submissions 